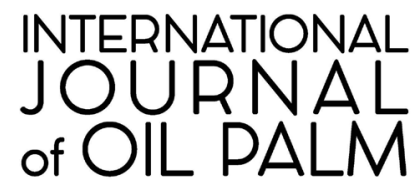

Volume 1, Number 1, January 2018

Page 18-27

ISSN: 2599-3496 print

ISSN: 2614-2376 online

\title{
Prospecting of Mannan Degrading Bacteria on Treating Palm Kernel Meal
}

\author{
Ludovika Jessica Virginia', Yepy Hardi Rustam¹, Griselda Herman Natadiputri', \\ Antonius Suwanto ${ }^{2 *}$
}

${ }^{1} \mathrm{PT}$. Wilmar Benih Indonesia, Cikarang 17530, Indonesia

${ }^{2}$ Bogor Agricultural University, Bogor 16680, Indonesia

\begin{abstract}
Palm kernel meal (PKM) is one of the most abundant by-products from oil palm industries. Although PKM can be used as ruminant feed but unfortunately it can not be applied directly as chicken feed due to its complex structure and lack of mannan degrading enzyme in chicken. Manan is a complex molecule composed of linear mannan, glucomannan, galactomannan, and galactoglucomannan and most nutrition contained in PKM was trapped in mannan structure. To increase the economic value of PKM, utilization of mannan degrading enzyme in pretreatment process of PKM before applying as chicken feed is required. We report here that isolation of potential mannanase as well as its prospective toward application in PKM was successfully conducted in this study. Mannanase producing bacteria (CK7) harboring wild type $\beta$-mannanase activity at $48.03 \mathrm{U} \mathrm{mL}^{-1}$ was obtained and identified as Bacillus subtilis isolate qd386 (accession number EF473134) with $96.7 \%$ pairwise identity through $16 \mathrm{~s}$ amplification. Over expression in Pichia pastoris system by pPICZaA as vector and KM71 as host (P-CK7) improved its activity into $4207.56 \mathrm{U} \mathrm{mL}^{-1}$ and $5000 \mathrm{U} \mathrm{mL}^{-1}$ within fed batch fermentation at $7.5 \mathrm{~L}$ and $500 \mathrm{~L}$, respectively. Recombinant manCK7 generated from P-CK7 was reported as the major expressed extracellular protein through SDS-PAGE in this study, thus make it more beneficial and attractive for further application study due to reduction of cell breaking process. Preliminary study on manCK7 application to PKM showed a promising result with a significant sugar released observed between PKM which treated with buffer, commercial enzyme, and manCK7 for 89 umole, $460.6 \mu$ mole, and $518.2 \mu$ mole, respectively.
\end{abstract}

Keywords: Bacillus subtilis, fed-batch fermentation, mannanase, oil palm, Pichia pastoris

\section{INTRODUCTION}

Indonesia is one of the world's largest producers of palm oil and the practical benefits offered by palm oil have become

${ }^{*}$ Corresponding author:

Department of Biology, Faculty of Mathematics and Natural Sciences,

Dramaga Campus, Bogor Agricultural University, Bogor 16680, Indonesia

E-mail: asuwanto@indo.net.id a ubiquitous part of the lives of consumers. Along side with the growth of palm oil, the industry has been the economy's most valuable agriculture export sector for the past decade as well as has helped pull many out of poverty. Other than palm 
oil as the main product from oil palm industry, the whole processes in the plant also generate other products such as palm kernel oil (PKO) as well as palm kernel meal (PKM) as its derivates.

Palm kernel meal is one of the most abundant by-products from oil palm industries (Yan 2009). Palm kernel meal is commonly used as animal feed for dairy cattle because of its high protein content therefore it is a reasonably good economic feed for cattle, both for fattening and supplementary feeding. It has effectively reduced the cost of milk production due to its ability to substitute of costly imported feedstuffs like soybean meal and ground maize. Although PKM can be used as ruminant feed but unfortunately it can not be applied directly as chicken feed because of its complex structure and lack of mannan degrading enzyme in chicken. Therefore, to increase the economic value of PKM, utilization of mannan degrading enzyme in pretreatment process of PKM before applying as chicken feed is required.

Manan is a complex molecule composed of linear mannan, glucomannan, galactomannan, and galactoglucomannan. In glucomannan, mannose residues are interspersed by $\beta$-1,4-linked glucose, and single galactosyl residues are $\alpha-1,6$ - linked to the mannan backbone in galactomannan (Fu et al. 2009). Mannanase is degrading enzymes that convert mannan and galactomannan into manose (Aurora et al. 2003). Mannanases are useful in many fields including biobleaching of pulp (Rattanasuk \& Cairns 2009) and detergent industry (Gubitz et al. 1997), bioconversion of biomass wastes to fermentable sugars (Chandrakant \& Bisaria 1998), upgrading of animal feed stuff (Ray et al. 1982), valuable food sweetener and additives (Tomotari 1990), and have a potential application for mannooligosaccharide preparation to be used as prebiotic (Phothichitto et al. 2006).
Betamannanase (1,4- $\beta$-D-mannan mannanohydrolase) catalyzes the hydrolysis of $\beta-1,4$ mannose linkages of the backbone of $\beta$-mannans (Marga et al. 1996).

Since most nutrition contained in PKM was trapped in mannan structure, therefore there is urgency to utilize mannanase in order to release the nutritive compound, especially in terms of its application in broiler feed. Supported by mannanase demand in broiler feed industry, the objective of this research focused on isolation of potential mannanase as well as its prospective toward application in PKM as broiler feed. Sampling was conducted in palm oil mill (PT. Multi Nabati Asahan, Kuala Tanjung, North Sumatra Region) at the area which frequently exposed with Palm Kernel Meal, such as PKM storage area, Palm Kernel Oil processing plant, etc. Mannanase producing bacteria, especially Bacillus sp. (Mabrouk \& Ahwany 2008; Xu et al. 2009) was preferable during screening process due to some considerations such as commonly known as potential mannanase producers, generally recognize as safe (GRAS), robust which reduce cost for specific handling, and easy to grow. Alongside with the preferences of the origin towards mannanase producing bacteria, expression system through Pichia pastoris was also desired due to its ability to secrete most of produced recombinant enzyme in media which deduct post harvesting cost such as cell breaking, eliminate antibiotic usage due to targeted sequence will be integrated into $P$. pastoris genome, and tightly regulated inducible AOX promoter. Therefore, once the main focus of isolating mannanase gene has been accomplished; further study towards high expression and potential application was conducted using $P$. pastoris expression system harboring targeted $\beta$-mannanase sequence. 


\section{MATERIALS AND METHOD}

\section{Screening Medium}

Sampling was conducted in several spots in palm oil mill area. Selective medium containing yeast extract $0.2 \%$, Tryptone $0.2 \%, \mathrm{MgSO}_{4} 0.02 \%, \mathrm{KH}_{2} \mathrm{PO}_{4}$ $0.14 \%,\left(\mathrm{NH}_{4}\right)_{2} \mathrm{SO}_{4} 0.1 \%$, and locust bean gum (LBG) $0.3 \%$ was used in both solid and liquid form for qualitative and quantitative measurement, respectively. Qualitative enzyme activity was determined by the clear zone generated from each single colony while quantitative enzyme activity was measured by DNS method as described by Miller 1959 whereas one unit of $\beta$-mannanase activity is defined as the amount of enzyme required to produce one $\mu$ mole of reducing sugar per minute.

\section{Strain and Plasmid}

The Escherichia coli strain DH5a was used as host for cloning vector as well as shuttle vector propagation. The pGEM-T ${ }^{\circledR}$ easy vector purchased from Invitrogen was used for DNA cloning procedures, whereas pPICZ $\alpha A$ (Invitrogen) was used for heterologous expression of recombinant $\beta$-mannanase. The Pichia pastoris strain KM71 (Invitrogen) was used as host for recombinant $\beta$-mannanase production.

\section{Mannanase Cloning}

Genome extraction using Wizard ${ }^{\circledR} \mathrm{Ge}$ nomic Purification Kit purchased from Promega was applied and identification towards $16 \mathrm{~s}$ amplification was conducted for the most potential colony with high mannanase activity. Specific primer (CHF 5'-GTACGCCATATGTTTAAGAAACATACGATCTCTTTGC-3'; CHR 5'-GTACGCCTCGAGTTCAACGATTGGCGTTAAAGAATC-3') was designed in order to amplify targeted $\beta$-mannanase sequence and TOPO-TA cloning was conducted using pGEM-T easy vector and $E$. coli
DH5a as host. Positive transformant was selected through blue-white screening through Luria Agar medium containing Ampicilin (100 ug mL $\mathrm{L}^{-1}$ ) and X-gal. Further bioinformatic analysis was applied to determine the novelty or similarity towards other published sequence in genebank.

\section{Mannanase Expression}

Cloned mannanase gene from pGEM-T easy vector was further expressed in $P$. pastoris expression system through pPICZ $\alpha A$ as vector and $P$. pastoris KM71 as host. Modified CHF-CHR primer with additional restriction site (EcoRI for CHF and Notl for CHR) was designed in order to amplify the targeted sequence from pGEM-T easy and further construction was done in pPICZaA vector. Escherichia coli $\mathrm{DH} 5 \alpha$ was used to propagate the constructed pPICZ $\alpha$ A with targeted mannanase sequence. Transformation into $P$. pastoris KM71 was performed by electroporation method with linear pPICZaA harboring mannanase sequence vector digested with Sacl. Positive transformant was screened by using luria agar low salt medium containing zeocin $\left(25 \mu \mathrm{g} \mathrm{mL}{ }^{-1}\right.$ ) and yeast potato dextrose (YPD) containing $100 \mu \mathrm{g} \mathrm{mL}^{-1}$ zeocin for both $E$. coli DH5a-pPICZaA-Mannanse and P. pastoris-pPICZaA-Mannanase, respectively.

Methanol as cheap solvent was used as inducer since Pichia pastoris expression system was driven under AOX promoter. In batch fermentation, buffer complex glycerol medium (BMGY) medium was used to cultivate the recombinant $P$. pastoris KM71 harboring $\beta$-mannanase gene and buffer complex methanol medium (BMMY) medium was used as induction medium. As much as 3\% (v/v) methanol was added every 24 hour to maintain the recombinant mannanase production (Promdonkoy et al. 2009). Detail protocol for recombinant enzyme production followed as suggested in the manual in- 
struction from Invitrogen ${ }^{\mathrm{TM}}$. Up-scale recombinant enzyme production was conducted through fed-batch fermentation using 7.5 L vessel bioreactor (New Brusnwick BioFlo ${ }^{\circledR} /$ Celligen $^{\circledR} 115$ ) using Basal Salt Medium containing $\mathrm{CaSO}_{4} \cdot 2 \mathrm{H}_{2} \mathrm{O} 0.9$ $\mathrm{g} \mathrm{L}^{-1}, \mathrm{~K}_{2} \mathrm{SO}_{4} 14.67 \mathrm{~g} \mathrm{~L}^{-1}, \mathrm{MgSO}_{4} \cdot 7 \mathrm{H}_{2} \mathrm{O}$ $14.9 \mathrm{~g} \mathrm{~L}^{-1}, \mathrm{KOH} 4.13 \mathrm{~g} \mathrm{~L}^{-1}$, glycerol $50 \mathrm{~g}$ $\mathrm{L}^{-1}$, phosphoric acid $85 \% 45.1 \mathrm{~g} \mathrm{~L}^{-1}$, histidine $1 \mathrm{~g} \mathrm{~L}^{-1}$, and trace element $4 \mathrm{~mL} \mathrm{~L}^{-1}$. Protocol for fed-batch fermentation was followed Charoenrat et al. ( 2013) before further optimized.

\section{Enzyme Activity}

DNS method was used to measure reducing sugar obtained from the reaction, and enzyme activity was determined based on equity derived from mannose standard curve. As much as $1 \%$ of LBG (Sigma) was used as substrate, and enzyme incubation was conducted in $50{ }^{\circ} \mathrm{C}$ for 10 minutes.

\section{PKM Application}

Palm kernel meal was obtained from PT. MNA and assay was conducted with $5 \mathrm{~g}$ and $250 \mathrm{~g}$ of PKM as substrate for laboratory and up scale trial, respectively. Incubation time was last up to 6 hours in $50{ }^{\circ} \mathrm{C}$ with phosphate buffer $\mathrm{pH} 7.0$ as solvent.

\section{RESULT AND DISCUSSION}

Screening from area frequently contacted with PKM, resulted in lots of mannanase producing bacteria where among several isolates, there was one colony labeled as CK7 which gave the most promising result for $48.03 \mathrm{U} \mathrm{mL}^{-1} \pm 0.02$ under standard assay condition using LBG as substrate. In order to ensure the ability of mannanase CK7 (manCK7) enzyme could work under applied condition in PKM, a preliminary trial was conducted by incubating PKM with 3 solvents; water, cultivated CK7 in Luria Bertani, and cultivated CK7 in liquid selective medium, where the comparison between PKM and solvent is $1: 1$. Obtained reducing sugar was shown in Figure 1 where manCK7 confirmed its ability to degrade mannan into reducing sugar with extracellular expressed enzyme. Experiment using Luria Bertani as medium also informed that manCK7 was not produced constitutively, instead required presence of LBG in order to produce $\beta$-mannanase.

Identification through $16 \mathrm{~s}$ amplification showed that CK7 has $96.7 \%$ pairwise identity with Bacillus subtilis isolate qd386 (accession number EF473134). Specific designed primers succeed in amplifying mannanase gene (1089 bp) and bioinformatic analysis illustrated that 366 amino acid hit $98 \%$ similarity to $\beta$-mannosidase from Bacillus subtilis (WP0326774581), which belongs to glycosylhydrolase family GH26, according to the CAZy (CArbohydrate-Active EnZymes) databank (Cantarel et al. 2009). Cloning into $P$. pastoris system was desired in order to overexpressed manCK7, alongside with other advantages derived from $P$. pastoris system which previously described (Li et al. 2007; Ahmad et al. 2014; Mellitzer et al. 2012). Vector pPICZaA was employed and construction of pPICZ $\alpha A-m a n C K 7$ was obtained (Figure 2). Integration of pPICZaA-manCK7 into P. pastoris KM71 (P-CK7) was successfully conducted and recombinant manCK7 was produced by using BMGY-BMMY medium. Within batch fermentation through 3 days of $\mathrm{MeOH}$ induction, $\mathrm{P}-\mathrm{CK} 7$ could generate $1281 \mathrm{U} \mathrm{mL} \mathrm{m}^{-1} \pm 137$ recombinant manCK7 which 26.7 fold higher compare to wild type manCK7. Protein concentration in recombinant manCK7 was $0.18 \mathrm{mg} \mathrm{mL}^{-1}$ \pm 0.008 which made the specific activity of recombinant manCK7 was $8542.2 \mathrm{U}$ $\mathrm{mg}^{-1}$. Protein profile of recombinant manCK7 was given in Figure 3, where 
SDS-PAGE showed manCK7 at around $42 \mathrm{KDa}$ which was confirmed as the main expressed protein.

Over expression through Pichia pastoris $\mathrm{KM} 71$ system with $\mathrm{pPICZ} \alpha \mathrm{A}$ vector has been widely known to secrete most of the recombinant protein into extracellular, and it was confirmed by comparing both enzyme activity from supernatant and pellet of BMMY induction medium which was shown in Figure 4. Specific activity acquired from supernatant was set to be $100 \%$ whereas mannanase activity from pellet was only $3.5 \%$.

Since over expression within Pichia pastoris KM71 system in laboratory

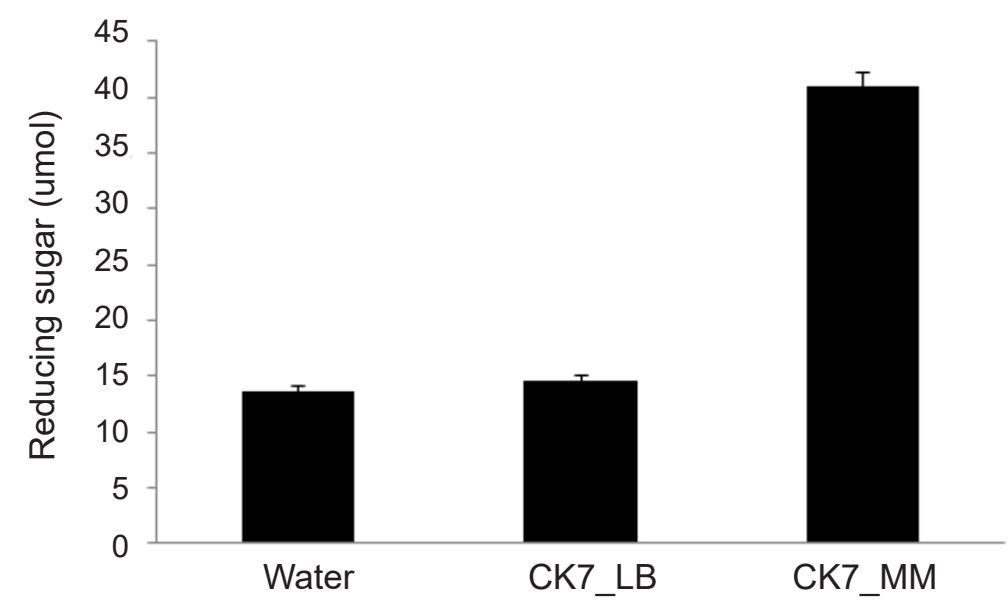

Figure 1 Incubated palm kernel meal with various solvent in $50^{\circ} \mathrm{C}$ for 6 hours and dried in $80^{\circ} \mathrm{C}$ for overnight. CK7_LB = mannanase derived from CK7 in Luria Bertani medium, CK7_MM = mannanase derived from $\mathrm{CK} 7$ in production medium containing locust bean gum.

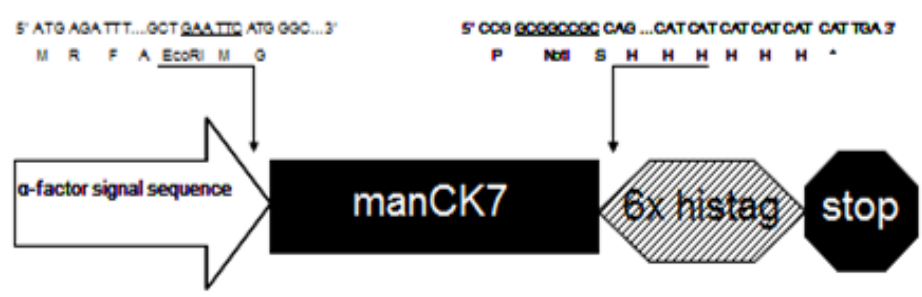

Figure 2 Construction of manCK7 in pPICZaA.

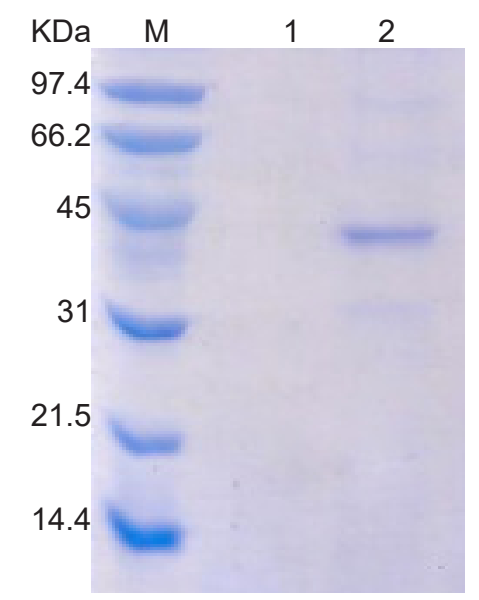

Figure 3 SDS-PAGE profile of recombinant manCK7 derived from P-manCK7. $\mathrm{M}=$ marker, well $1=$ non-methanol $(\mathrm{MeOH})$ induction, well $2=2$ days $\mathrm{MeOH}$ induction. 
scale showed a promising result, further study to improve manCK7 activity was designed. Despite conducting genetic modification or molecular engineering to improve enzyme activity (Couturier et al. 2013), optimization in production step was considered a crucial part to support application of manCK7 in the future. Beside, optimized production could increase recombinant enzyme activity thus up scale production system by utilizing fedbatch fermentation was considered suitable for this study. Optimization of fedbatch fermentation in $7.5 \mathrm{~L}$ bioreactor for 148 hours resulted in the increment of recombinant manCK7 activity into 4207.56 $\mathrm{U} \mathrm{mL} \mathrm{m}^{-1}$ which was 3.3 fold higher compare to batch fermentation whereas its specific activity reached $14,058 \mathrm{U} \mathrm{g}^{-1}$. When compared to other recombinant mannanase expressed in $P$. pastoris system, recombinant manCK7 generated higher enzyme activity (4207.56 U mL-1) where $\beta$-mannanase from $B$. subtilis MA139 showed $230 \cup \mathrm{mL}^{-1}$ (Qiao et al. 2010), $\beta$-mannanase from $B$. subtilis strain $\mathrm{G} 1$ obtained 224 $\mathrm{U} \mathrm{mL}^{-1}$ (Vu et al. 2012), and $\beta$-mannanase originated from $\mathrm{B}$. subtilis $\mathrm{N} 16-5$ showed enzyme activity at $32.2 \mathrm{U} \mathrm{mL}^{-1}$ ( $\mathrm{He}$ et al. 2008).

Pilot scale production up to $500 \mathrm{~L}$ bioreactor was also developed in order to accommodate manCK7 application for future application, and $5000 \mathrm{U} \mathrm{mL}^{-1}$ enzyme activity was achieved with protein content $0.283 \mathrm{~g} \mathrm{~L}^{-1}$. Approximately $250 \mathrm{~L}$ of supernatant was harvested with specific activity $17,668 \mathrm{U} \mathrm{g}^{-1}$. Ultrafiltration and formulation with $25 \%$ glycerol was conducted for more convenience handling and longer shelf life, respectively. However the concentrated enzyme seems lost some of its specific activity from 17,667 $\mathrm{U}$ $\mathrm{g}^{-1}$ into $12,844 \mathrm{U} \mathrm{g}^{-1}$, after it was concentrated. This could happen due to long time of microfiltration and ultrafiltration which was not maintained in cold temperature. Summary of enzyme activity obtained from each production system was given in Figure 5.

Experiment of recombinant manCK7 to treat PKM also performed in laboratory scale at $5 \mathrm{~g}$ to collect preliminary data regarding time course required for enzyme incubation, shaking frequency, and total sugar release. Duration of incubation time at $50{ }^{\circ} \mathrm{C}$ was shown in Figure 6 , where 16 hours gave the highest reducing sugared when measured by DNS method. However, released sugar from PKM incubated for 4 hours to 6 hours was not significantly different; this might happen due to enzyme reaction rate was reduced overtime although total sugar released kept rising

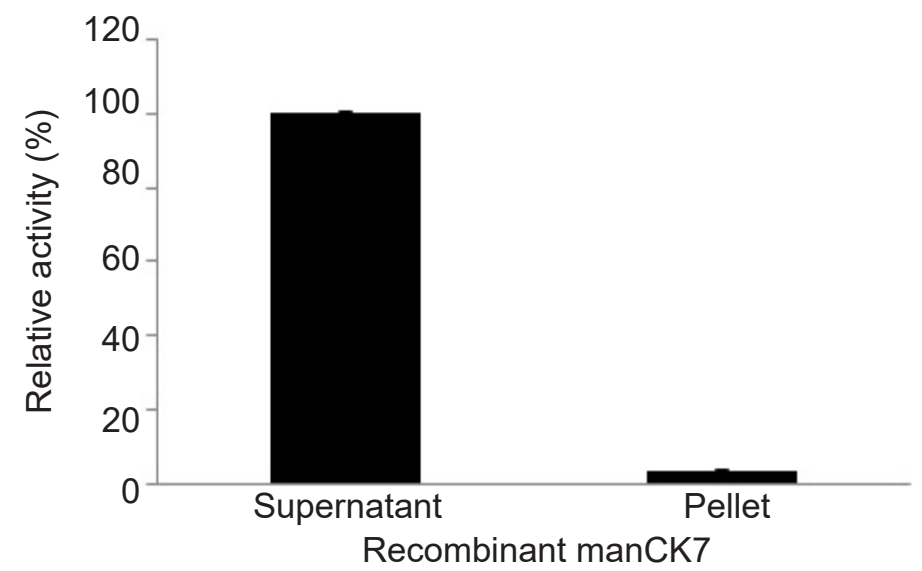

Figure 4 Comparison of specific activity generated from P-ManCK7 from supernatant and pellet. 


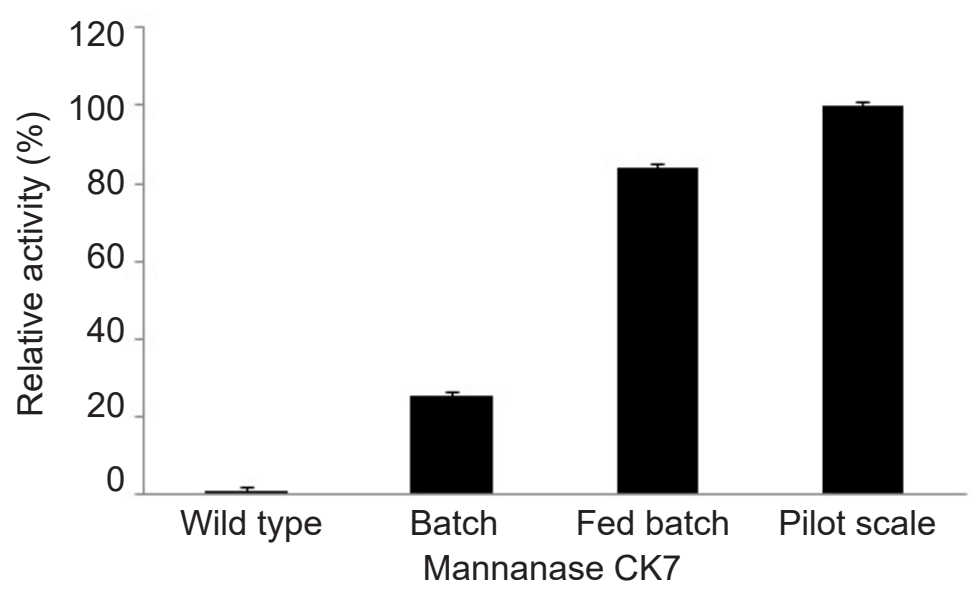

Figure 5 Comparison of manCK7 activity between wild type and recombinant P-manCK7 through various production type. Wild type $=$ manCK7 produced from wild type CK7 in selection medium at $50 \mathrm{~mL}$ total volume; batch = manCK7 produced from P-manCK7 in buffer complex glycerol medium $50 \mathrm{~mL}$ followed by buffer complex methanol medium $10 \mathrm{~mL}$; fed batch = manCK7 produced from P-manCK7 in $5 \mathrm{~L}$ basal salt medium (BSM); pilot scale $=$ manCK7 produced from P-manCK7 in $360 \mathrm{~L} \mathrm{BSM}$ at 500 L bioreactor tank.
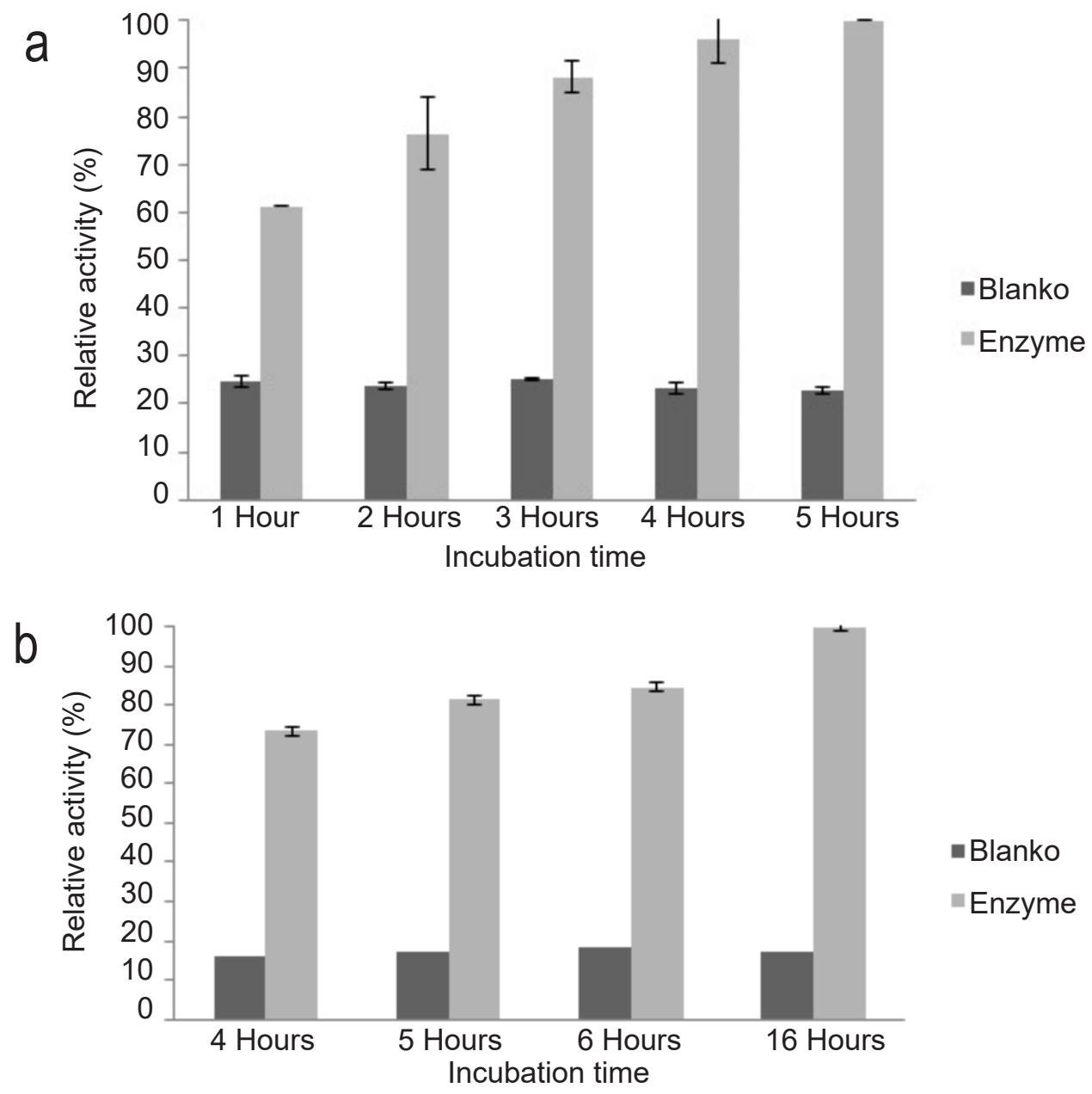

Figure 6 Experiment on incubation time of recombinant manCK7 for palm kernel meal treatment: a. at 1 hour until 5 hour, and b. 4 hour until 16 hour. Blanko $=\mathrm{PKM}$ treated with buffer phosphate $\mathrm{pH} 7$, enzyme $=$ PKM treated with recombinant manCK7. 
when incubation time was prolonged up to 16 hours. Considering time and cost efficiency, 6 hours incubation time was used in this preliminary study.

Incubation for treating PKM with manCK7 was carried out under limited water utilization, which was expected to reduce drying cost in the future application. Within limited water availability, enzyme treated PKM was reckoned as solid substrate fermentation, therefore shaking frequency need to be examined to maintain complete and consistent exposure of PKM to manCK7. Data informed in Figure 7 showed that continues shaking gave the highest of total released sugar released $(100 \%)$, where enzyme treated PKM with manually shaking every 10 minutes and 4 hour are at $85 \%$ and $80 \%$, respectively.

The most detrimental factor in manCK7 study for PKM application was the total sugar released after PKM was treated with manCK7. For this experiment, up scale to $250 \mathrm{~g}$ PKM as substrate was employed and treatment was compared between PKM which incubated by manCK7 and commercial mannanase. Palm kernel meal treated with buffer was set as blank and released $89 \mu$ mole of total sugar and PKM which treated with commercial mannanase released 460.6 mmole, whereas manCK7 treated PKM resulted as the highest total sugar released at 518.2 $\mu$ mole. Relative sugar released among these 3 PKM is shown in Figure 8.

This study informed that manCK7 has a great potential to degrade complex mannan structure, and PKM which is consisted mainly of $\beta$-mannan structure was a suitable substrate for this enzyme. This hypothesis was supported by the preliminary study on manCK7 for PKM treatment which showed a promising result for further application such as treating PKM for broiler feed and others. However, further exploration toward PKM utilization for broiler feed is required.

\section{CONCLUSION}

Mannanase producing bacteria was successfully isolated and $16 \mathrm{~s}$ identification showed $96.7 \%$ similarity to Bacillus subtilis. Mannanase gene obtained from this isolate was further labeled as manCK7 with $98 \%$ similarity to $\beta$-manno-

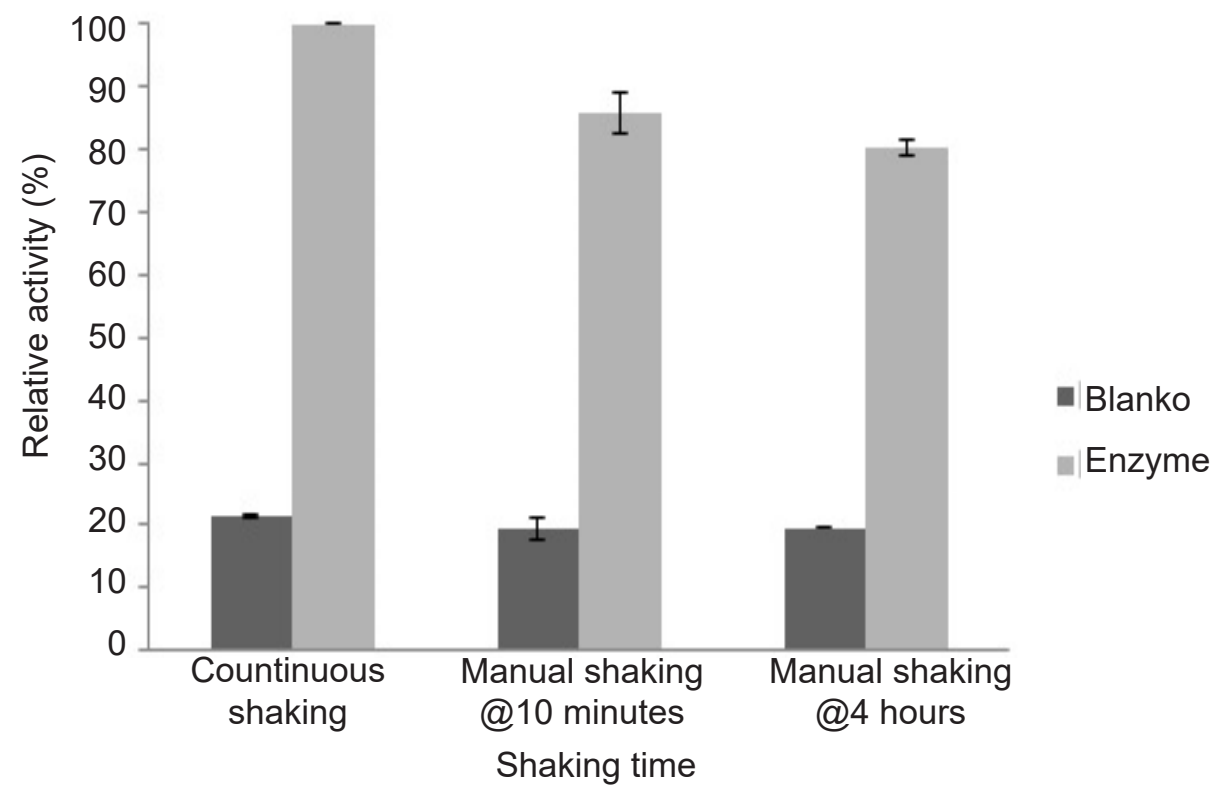

Figure 7 Comparison of total sugar released by continuous shaking, manual shaking every 10 minutes, and manual shaking every 4 hours. 


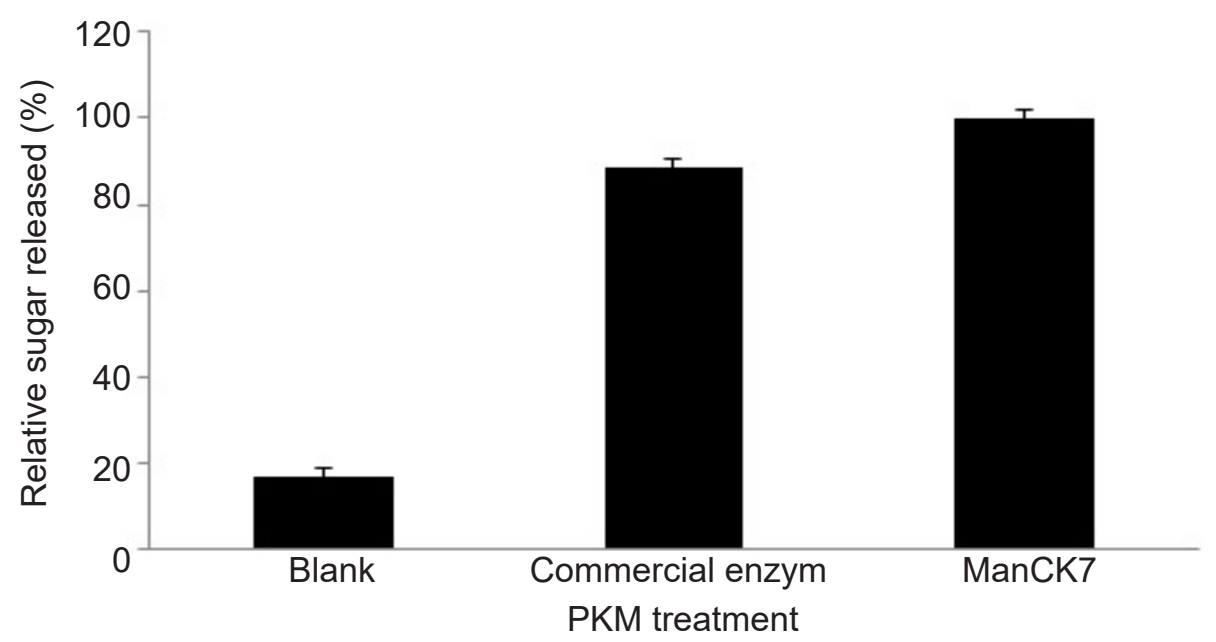

Figure 8 Comparison of reducing sugar released with 3 types palm kernel meal treatment; blank (phosphate buffer pH 7.0), commercial enzyme, and manCK7.

sidase $B$. subtilis and had $48.03 \mathrm{U} \mathrm{mL}^{-1}$ enzyme activity. Over expression was conducted under $P$. pastoris system which improved activity up to $4,207.56 \mathrm{U} \mathrm{mL}^{-1}$ in fed batch fermentation at $7.5 \mathrm{~L}$ and 5000 $\mathrm{U} \mathrm{mL} \mathrm{m}^{-1}$ in pilot scale production of $500 \mathrm{~L}$. Preliminary study on manCK7 application to PKM showed a promising result since a significant sugar released was observed between PKM which treated with buffer (89 $\mu$ mole) and manCK7 (518.2 $\mu$ mole). Treatment of PKM with commercial enzyme was also resulted in a lower sugar released for 460.6 umole, compare to those which treated with manCK7.

\section{REFERENCES}

Ahmad M, Hirz M, Pichler H, Schwab H. 2014. Protein expression in Piscia pastoris: Recent achievements and perspectives for heterologous protein production. Appl Microbiol Biotechnol. 98(12):5301-5317.

Aurora DD, Lestari Y, Meryandini A. 2003. Identification of mannanase producing bacteria and characterization of the enzyme. J Microbiol Indones. 8(1):31-33. Cantarel BL, Coutinho PM, Rancurel C, Bernard T, Lombard V. 2009. The carbohydrate-active enzyme database
(CAZy): an expert resource for glycogenomics. Nucleic Acids Res. 37:233238.

Chandrakant P, Bisaria VS. 1998. Simultaneous bioconversion of cellulose and hemicellulose to ethanol. Crit Rev Biotechnol. 18(4):295-331.

Charoenrat T, Khumruaengsri N, Promdonkoy P, Rattanaphan N, Euwilaichitr L, Tanapungpipat S, Roongsawang N. 2013. Improvement and recombinant endoglucanase produced in $\mathrm{Pi}$ chia pastoris KM71 through the use of synthetic medium for inoculum and $\mathrm{pH}$ control of proteolysis. J Biosci Bioeng. 116(2):193-198.

Couturier M, Féliu J, Bozonnet S, Roussel A, Berrin J-G. 2013. Molecular engineering of fungal $\mathrm{GH} 5$ and $\mathrm{GH} 26$ beta-(1,4)-mannanases toward improvement of enzyme activity. PLoS ONE. 8(11):e79800. DOI:10.1371/journal.pone.0079800.

Fu X, Huang X, Liu P, Lin L, Wu G, Li C, Feng C, Hong Y. 2009. Cloning and characterization of a novel mannanase from Paenibacillus sp. BME-14. J Microbiol Biotechnol. 20(3):518-524.

Gubitz GM, Lischnig T, Stebbing D, Saddler JN. 1997. Enzymatic removal of 
hemicellulose from dissolving pulps. Biotechnol Lett. 19:491-495.

He X, Liu N, Li W, Zhang Z, Zhang B, Ma Y. 2008. Inducible and constitutive expression of a novel thermostable alkaline $\beta$-mannanase from alkaliphilic Bacillus sp. N16-5 in Pichia pastoris and characterization of the recombinant enzyme. Enzyme Microbiol Technol. 43(1):13-18.

Li P, Anumanthan A, Gao XG, llangovan K, Suzara W, Düzgüneş N, Renugupalakrishnan V. 2007. Expression of recombinant proteins in Pichia pastoris. Appl Biochem Biotechnol. 142(2):105124.

Mabrouk MEM, Ahwany AMDE. 2008. Production of $\beta$-mannanase by Bacillus amylolequifaciens 10A1 cultured on potato peels. Afr $\mathrm{J}$ Biotechnol. 7(8):1123-1128.

Marga F, Ghakis C, Dupont C, Morosoli R, Kluepfel D. 1996. Improved production of mannanase by Streptomyces lividans. J Appl Environ Microbiol. 62(12):4656-4658.

Mellitzer A, Weis R, Glieder A, Flicker K. 2012. Expression of lignocellulolytic enzymes in Pichia pastoris. Microbial Cell Factories. 11:61. DOI:10.1186/14752859-11-61.

Miller L. 1959. Use of dinitrosalicylic acid reagent for determination of reducing sugar. Anal Chem. 31(3):426-428.

Phothichitto K, Nitisinprasert S, Keawsompong S. 2006. Isolation, screening and identification of mannanase producing microorganisms. Kasetsart $\mathrm{J}$ Nat Sci. 40:26-38.
Promdonkoy P, Tang K, Sornlake W, Harnpicharnchai P, Kobayashi RS, Ruanglek V, Upathanpreecha T, Vesaratchavest M, Eurwilaichitr L, Tanapongpipat S. 2009. Expression and characterization of Aspergillus thermostable phytase in Pichia pastoris. FEMS Microbiol Lett. 290:18-24.

Qiao J, Rao Z, Dong B, Cao Y. 2010. Expression of Bacillus subtilis MA139 $\beta$-mannanase in Pichia pastoris and the enzyme characterization. Appl Biochem Biotechnol. 160(5):1362-1370.

Rattanasuk S, Cairns MK. 2009. Chryseobacterium indologenes, novel mannanase-producing bacteria. Songklanakarin J Sci Technol. 31(4):395-399.

Ray S, Pubols MH, McGinnis J. 1982. The effect of a purified guar degrading enzyme on chicken growth. Poultry Sci. 61(3):488-494.

Tomotari M. 1990. Bifidobacteria and their role in human health. J Microbiol Indones. 6(4):263-268.

Vu TT, Quyen DT, Dao TT, Nguyen ST. 2012. Cloning, high-level expression, purification, and properties of a novel endo- $\beta-1,4-m a n n a n a s e$ from Bacillus subtilis G1 in Pichia pastoris. J Microbiol Biotechnol. 22(3):331-338.

Xu B, Duan L, Tang XH, Li JJ, Mu YL, Yang YJ, Huang Z. 2009. Characterization of 6 Bacillus subtilis $\beta$-mannanases and their genes. Afr J Biotechnol. 8(18):4316-4324.

Yan FY, Krishniah D, Rajin M, Bono A. 2009. Cellulose extraction from palm kernel cake using liquid phase oxidation. J Eng Sci Technol. 4(1):57-68. 